\title{
Influence of Tungsten on Dry Sliding Wear Behaviour of Sintered/Hot Extruded P/M Alloy Steels (Fe-C-W-Ti)
}

\author{
S. Senthur Prabu ${ }^{a}$, S. Prathiba ${ }^{b}$, M.A. Asokan ${ }^{a}$, MK Sreelekh ${ }^{a}$, Francis Steff $f^{a}$, Mounish Sai ${ }^{a}$ \\ ${ }^{a}$ School of Mechanical Engineering, VIT University, Vellore - 632014, India \\ ${ }^{b}$ Department of Chemical Engineering, St.Joseph's College of Engineering, Chennai -600119, India
}

Received: December 08, 2016; Revised: February 24, 2017; Accepted: May 21, 2017

\begin{abstract}
In the present scenario, Powder Metallurgy $(\mathrm{P} / \mathrm{M})$ is an established manufacturing process used to make components of complex geometries with high strength and tolerances by using incredible materials which are difficult to melt or form by other processes. The mechanical properties and microstructures will determine the component characteristic dependent on the final obtained density of sintered P/M alloy steels. An attempt has been made to investigate the dry sliding wear behaviour of sintered/hot extruded P/M alloy steels with Fe-1C as base material, W (Tungsten) and Ti (Titanium) as an alloying element. The wear test was carried out by using a pin-on-disc tribometer (ASTM G99) against EN 38 steel disc (HRC 60) with a constant sliding speed of $2 \mathrm{~m} / \mathrm{s}$ at normal loads of 30,50 and $70 \mathrm{~N}$ respectively. The microstructure of the as-sintered P/M alloy steels reveals the ferritic-pearlite structure whereas for hot extruded alloy steels the microstructure shows a combination of Widmanstatten type ferrite, pearlite and bainite. From the microstructure the presence of WC (tungsten carbide) embedded with $\mathrm{Ti}$ in the grain boundaries offers greater wear resistance of the hot extruded $\mathrm{P} / \mathrm{M}$ alloy steels. The common wear mechanism observed for hot extruded alloy steels is Delamination wear.
\end{abstract}

Keywords: P/M alloy steels; mass loss; sliding distance; Coefficient of friction; Sintered/ hot extruded.

\section{Introduction}

The steels produced through powder metallurgy $(\mathrm{P} / \mathrm{M})$ manufacturing process have immense potential for industrial applications. In view of requirements of mass production, lean manufacturing, improved reliability and replacing all traditional methods of metal forming operations because of its lesser energy consumption, maximum material utilization, low relative material wastage and competitive cost. Sintered low alloy steels through the $\mathrm{P} / \mathrm{M}$ route find several industrial applications in making components for machine parts, in the field of automobiles such as fasteners, bearings, gears, in the field of manufacturing such as tools, cutters, and also in the field of aerospace, defense, etc. Hortenhuber ${ }^{1}$ has found that the $\mathrm{P} / \mathrm{M}$ steel components are widely used in manufacturing of complex shaped machine elements such as gears, bearings mainly for wear loaded components like cam lobes etc., because of its self-lubricating capabilities and greater alloying possibility. Straffelini et al. ${ }^{2}$ investigated that $\mathrm{P} / \mathrm{M}$ materials such as gears or cams subjected to working conditions giving rise to sliding, rolling or abrasive wear, mainly depends on the hardness of the components. The strengthening of sintered P/M low alloy steels can be achieved through densification, alloying and heat treatment ${ }^{3}$. The wear mechanisms of $\mathrm{P} / \mathrm{M}$ alloy steel parts has similar

\footnotetext{
*e-mail: senthurprabu.s@vit.ac.in
}

properties compared to wrought materials, under the same tribological conditions, but the porosity plays a significant role in wear behaviour of alloy steels ${ }^{4,5}$. Wang et al. ${ }^{6}$ reported that quenched and tempered Mo-based low alloy P/M steel preforms has higher wear coefficient values compared to assintered preforms and also their sliding wear characteristics is considerably influenced by heat treatment. Dhanasekaran et al. ${ }^{7}$ studied about the addition of molybdenum di sulphide to the $\mathrm{Fe}-\mathrm{C}-\mathrm{Cu} \mathrm{P} / \mathrm{M}$ alloy and observed in increase in mechanical strength, hardness, coefficient of friction and also the wear resistance of the alloy steel during wear test. Lorella et al. ${ }^{8}$ investigated the sliding and abrasion wear behaviour of sintered Fe-C-Cr and Fe-C-Mo P/M alloy steels and concluded that the alloy containing Mo exhibits better dry sliding wear resistance compared to $\mathrm{Cr}$ added steel and also reported that the wear characteristics of alloy steels is mainly influenced by porosity, the alloy composition and sintering conditions. The addition of $\mathrm{TiC}$ found to enhance the wear resistance of high speed steel due to the formation of hard carbides rather than the addition of $\mathrm{MnS}$ and $\mathrm{CaF}_{2}$. On the other hand the latter improves self-lubricating property of the steel ${ }^{9}$. The influence of microstructure on impact and wear behavior of sintered $\mathrm{Cr}$ and Mo steels is studied by Molinari et al. ${ }^{10}$ and concluded that graphite with $\mathrm{Cr}$ increases the hardenability by the formation of bainitic-martensitic microstructure after sintering with normal cooling. Bose et al. ${ }^{11}$ investigated that the addition of $\mathrm{W}$ to $\mathrm{P} / \mathrm{M}$ alloys could 
enhance the wear resistance due to the formation of hard phases in the microstructure. The hardened carbide based $\mathrm{P} / \mathrm{M}$ alloy steels could be the best choice for replacing the HSS in view of the economics of production. Senthur prabu et al. ${ }^{12}$ investigated that the dry sliding wear behaviour of sintered/extruded $\mathrm{W}$ and Ti alloyed plain carbon steel and resulted that the Ti alloyed steel has more wear resistance compared to $\mathrm{W}$ alloyed steel. The microstructure of extruded Fe-1\%C-1\%W steel shows the Widmanstatten ferrite and ferrite-cementite matrix (alternate lamellas) whereas in Fe-1\%C-1\%Ti extruded alloy steel shows a combination of Widmanstatten type ferrite, pearlite and bainite, which plays the main role in the $\mathrm{P} / \mathrm{M}$ alloy steels to enhance the wear resistance results in minimum mass loss compared to $\mathrm{W}$ based extruded alloy steel. In view of the emerging importance of low alloy $\mathrm{P} / \mathrm{M}$ steels in various applications stated above, and due to their potential high strength and economic structural applications, so it is important to have a complete understanding of the wear behavior of $\mathrm{P} / \mathrm{M}$ steels in order to evaluate their suitability for frictional wear applications.

Scanning the literature, it is evident that, for the dry sliding wear behavior of sintered/hot extruded P/M alloy steels with Fe-C alloy with $\mathrm{W}$ and Ti addition has not been reported hitherto.

In the present investigation, the dry sliding wear behavior of sintered/hot extruded $\mathrm{P} / \mathrm{M}$ alloy steels with $\mathrm{Fe}-1 \mathrm{C}$ as base material, $\mathrm{W}$ and $\mathrm{Ti}$ as alloying elements (Fe-1C-1W-1Ti, Fe-1C-2W-1Ti and Fe-1C-4W-1Ti) was studied. Potential applications of these steels are mainly used as tools, cutters, fasteners, bearing roller etc. requiring high strength, high hardness and wear resistance. The hot extruded steel pin of diameter $6 \mathrm{~mm}$ was subjected to dry sliding wear test on pin-on disc arrangement (ASTM G99) against EN 38 steel disc of Hardness HRC 60 with a constant sliding speed of $2 \mathrm{~m} / \mathrm{s}$ and at a normal load of 30,50 and $70 \mathrm{~N}$ respectively.

\section{Experimental Details}

Elemental powders of Iron (Fe), Graphite (C), Tungsten (W) and Titanium (Ti) have the particle size of 150, 5, 100 and $100 \mu \mathrm{m}$ were accurately weighed and mixed thoroughly in a pot mill for $10 \mathrm{hrs}$ to yield the alloy compositions of Fe-1C-1W-1Ti, Fe-1C-2W-1Ti and Fe-1C-4W-1Ti in wt. $\%$. The physical properties of elemental alloy powder such as apparent density, tap density, and flowability by using standard testing methods has been carried out and presented in table 1 . The blended powders of the alloy compositions were compacted into cylindrical billets of aspect ratio (height/diameter) of $1.5(\varnothing 25 \times 33 \mathrm{~mm})$ with the help of graphite lubricant at a pressure of $350 \mathrm{MPa}$ by using the hydraulic press of $100 \mathrm{~T}$ capacity. After the compaction, to avoid oxidation of the green compacts indigenously made aluminium, ceramic coating was applied immediately and dried for $24 \mathrm{~h}$. The dried green compacts were sintered in an argon purged inert atmosphere for a period of $120 \mathrm{~min}$ in tubular furnace (diameter and length is $70 \times 500 \mathrm{~mm}$ ) at 900 $\pm 1^{\circ} \mathrm{C}$. The sintered preforms were subject to hot extrusion at a temperature of $1050^{\circ} \mathrm{C}$ to get cylindrical pin of $10 \mathrm{~mm}$ diameter as shown in the figure 1. Further the hot extruded specimens machined off to obtain the ASTM standard size of $6 \mathrm{~mm}$ diameter pin. The hardness values of both as-sintered and hot extruded P/M alloy steels are given in table 2. Standard metallography procedure has been adopted, i.e. the pin surface were polished with different grit sizes of emery sheets from 200 to 1000 and followed by disk polishing using alumina solution to obtain mirror finish of $1 \mu$ before the specimens subjected to wear test. Before the wear test, the head portion was cut off, and then the initial weight of the steel pin was measured using an electronic weighing balance (Mettler Toledo) of $0.0001 \mathrm{mg}$ accuracy. The dry sliding wear tests of hot extruded P/M alloy steel pins were conducted at a normal load of $30,50 \& 70 \mathrm{~N}$ with a sliding speed of $2 \mathrm{~m} / \mathrm{s}$ on the computer assisted Pin-on-disk tribometer against counter face EN 38 steel disc of Hardness HRC 60. To get the high precision results, the steel disc (counter face) was cleaned by acetone for each wear test. The mass loss was determined as the change in weight of the extruded steel pin measured accurately before and after the wear test. Coefficient of friction was also taken during the wear test from the tribometer. The wear mechanisms were studied by observing the worn out surfaces using both optical microscope and SEM.

\section{Results and Discussions}

\subsection{Hot Extrusion process of P/M steels alloyed with Tungsten and Titanium}

The figure 1(a-c) depicts the hot extruded $\mathrm{P} / \mathrm{M}$ plain carbon steels, alloyed with tungsten and titanium (Fe-1C1W-1Ti, Fe-1C-2W-1Ti and Fe-1C-4W-1Ti). During hot extrusion process the deformation level is maximum for the alloy steel which contains a low percentage of $\mathrm{W}$ in the base metal, i.e. the head portion in the extruded specimen is small (Figure 1 $(a, b)$ ) whereas for a higher percentage of tungsten $(4 \mathrm{~W})$ in the base metal of Fe-1C, the deformation level is low and very hard also for the same applied load due to the high hardness (the head portion is big), it is evident from the Figure 1c.

\subsection{Microstructure of as-sintered and hot extruded P/M steels alloyed with Tungsten and Titanium}

Figure 2(a, c, e) and 2(b, d, f) depicts the microstructure of as-sintered and hot extruded $\mathrm{P} / \mathrm{M}$ plain carbon steels alloyed with tungsten and titanium. The conventional structure of 
Table 1. Physical properties of elemental alloy powder

\begin{tabular}{lccccc}
\hline Sl. No. & Composition & Theoretical Density $(\mathrm{g} / \mathrm{cc})$ & Apparent Density $(\mathrm{g} / \mathrm{cc})$ & Tap Density $(\mathrm{g} / \mathrm{cc})$ & Flowability (s/g) \\
\hline 1 & Fe-1C-1W-1Ti & 7.62 & 3.04 & 3.48 & 0.50 \\
2 & Fe-1C-2W-1Ti & 7.74 & 3.08 & 3.43 & 0.52 \\
3 & Fe-1C-4W-1Ti & 7.80 & 3.12 & 3.47 & 0.53 \\
\hline
\end{tabular}
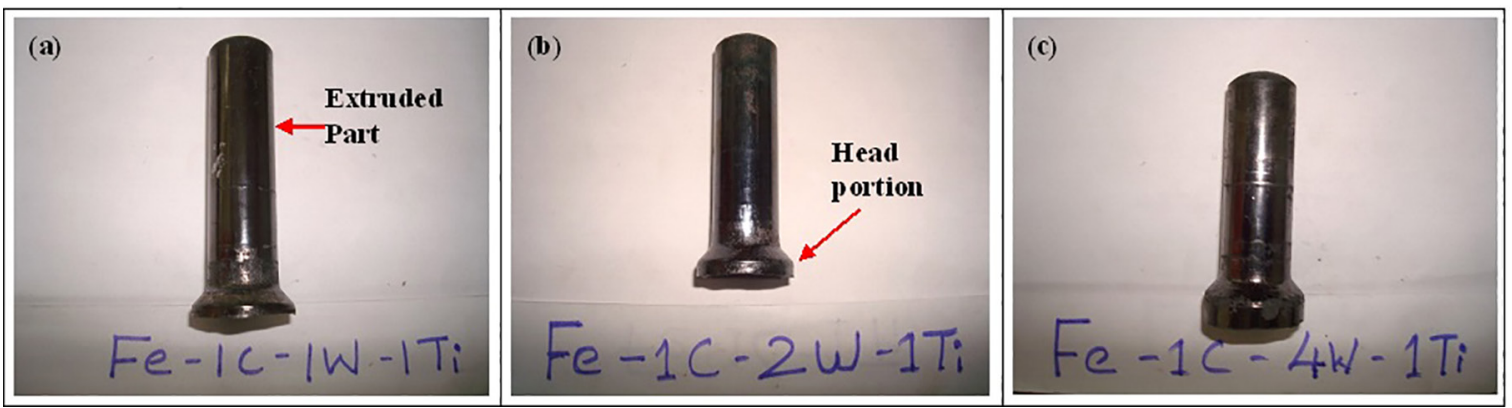

Figure 1. Extruded P/M alloy steels (a) Fe-1\%C-1\%W-1\%Ti; (b) Fe-1\%C-2\%W-1\%Ti; (c) Fe-1\%C-4\%W-1\%Ti

Table 2. Hardness values of $\mathrm{P} / \mathrm{M}$ alloy steels for both as-sintered and hot extruded

\begin{tabular}{llll}
\hline Sl. No. & Composition & $\begin{array}{l}\text { As-Sintered } \\
(\mathrm{HRF})\end{array}$ & $\begin{array}{l}\text { Hot Extruded } \\
(\mathrm{HRB})\end{array}$ \\
\hline 1 & Fe-1C-1W-1Ti & 80.56 & 91.55 \\
2 & Fe-1C-2W-1Ti & 86.62 & 93.81 \\
3 & Fe-1C-4W-1Ti & 88.44 & 94.36 \\
\hline
\end{tabular}

ferrite (white constituent) and pearlite (dark constituent) was observed in the microstructure of the as-sintered P/M alloy steels. The uniform distribution of $\mathrm{W}$ and Ti particles occupied the ferritic grain boundary areas in the base metal of $\mathrm{Fe}-1 \mathrm{C}$ and reveals the ferritic- pearlitic microstructure. From Figure 2e due to the more percentage of $\mathrm{W}$ addition, the WTiC particles embedded in the ferrite grain is bigger in size. As W and Ti is one of the well-known carbide former. The $\mathrm{W}$ and Ti carbides of alloying elements embedded along the ferritic grain boundaries strengthened the grain boundary region leads to enhance the wear resistance of the hot extruded $\mathrm{P} / \mathrm{M}$ steels. The microstructure of hot extruded $\mathrm{P} / \mathrm{M}$ steels (Figure 2(b, d, f) ) alloyed with $\mathrm{W}$ and Ti shows combination of Widmanstatten type ferrite, pearlite and bainite, might be possibly occurred at a higher temperature between $\mathrm{AC} 1$ and AC3 $\left(723-900^{\circ} \mathrm{C}\right)$ during extrusion. The grain boundaries get oriented along the extrusion direction. Figure 2(b, d) reveals a mixed microstructure of Widmanstatten ferrite and ferrite-cementite matrix (alternate lamellas) contributes the alloy (Fe-1C-1W-1Ti and Fe-1C-2W-1Ti) to thermal softening due to rise in interface temperature (between the specimen and the disc material) at higher loads because of lower hardness (table 2). Figure $2 \mathrm{f}$ reveals the presence of more harder secondary phase WTiC particles embedded in the ferrite-pearlite grains leads into Widmanstatten type ferrite and bainite structure thereby increase in hardness results in decrease of mass loss at higher loads, also it is evident from Figure 3c. Also, this might be one of the reasons for the reduction in deformation during hot extrusion process (Figure 1c). The coefficient of friction seems to be higher for W, Ti alloyed P/M steels due to the hard phase WTiC presence in the extruded microstructures.

\subsection{Dry sliding wear behaviour of sintered/hot extruded P/M steels alloyed with Tungsten and Titanium}

The dry sliding wear test was carried out and the mass losses were expressed in terms of material removal as a function of normal applied load and sliding distance. The wear curves (mass loss and frictional coefficient versus sliding distance) at a constant sliding velocity of $2 \mathrm{~m} / \mathrm{s}$ for an axial load of 30, 50 and $70 \mathrm{~N}$ were obtained.

Figure 3(a-c) depicts the dry sliding wear behaviour of sintered /hot extruded $\mathrm{P} / \mathrm{M}$ plain carbon steels, alloyed with tungsten and titanium $(\mathrm{Fe}-1 \% \mathrm{C}-1 \% \mathrm{~W}-1 \% \mathrm{Ti}, \mathrm{Fe}-1 \% \mathrm{C}-2 \% \mathrm{~W}-$ $1 \% \mathrm{Ti}, \mathrm{Fe}-1 \% \mathrm{C}-4 \% \mathrm{~W}-1 \% \mathrm{Ti}$ ) for different loads.

From the figure $3(\mathrm{a}-\mathrm{c})$ it was clearly observed that the mass loss increases gradually with sliding distance and applied load as per the general principle of wear "the wear rate is directly proportional to the applied load". The mass loss of Fe-1C-2W-1 Ti increases linearly irrespective of applied load and sliding distance compared to Fe-1C$1 \mathrm{~W}-1 \mathrm{Ti}, \mathrm{Fe}-1 \mathrm{C}-4 \mathrm{~W}-1 \mathrm{Ti}$ due to the presence of secondary phase hard WTiC, leads to the rise in interface temperature results in thermal softening of the material which cause propagation of micro-cracks, further lead to formation of wear fragments. As $\mathrm{W}$ and $\mathrm{Ti}$ is one of the well-known carbide former. The presence of hard phase is easily cracked under high applied loads and the worn products acts as hard impurity or a particle (third body) between mating surfaces and join in the wear process results in higher mass 

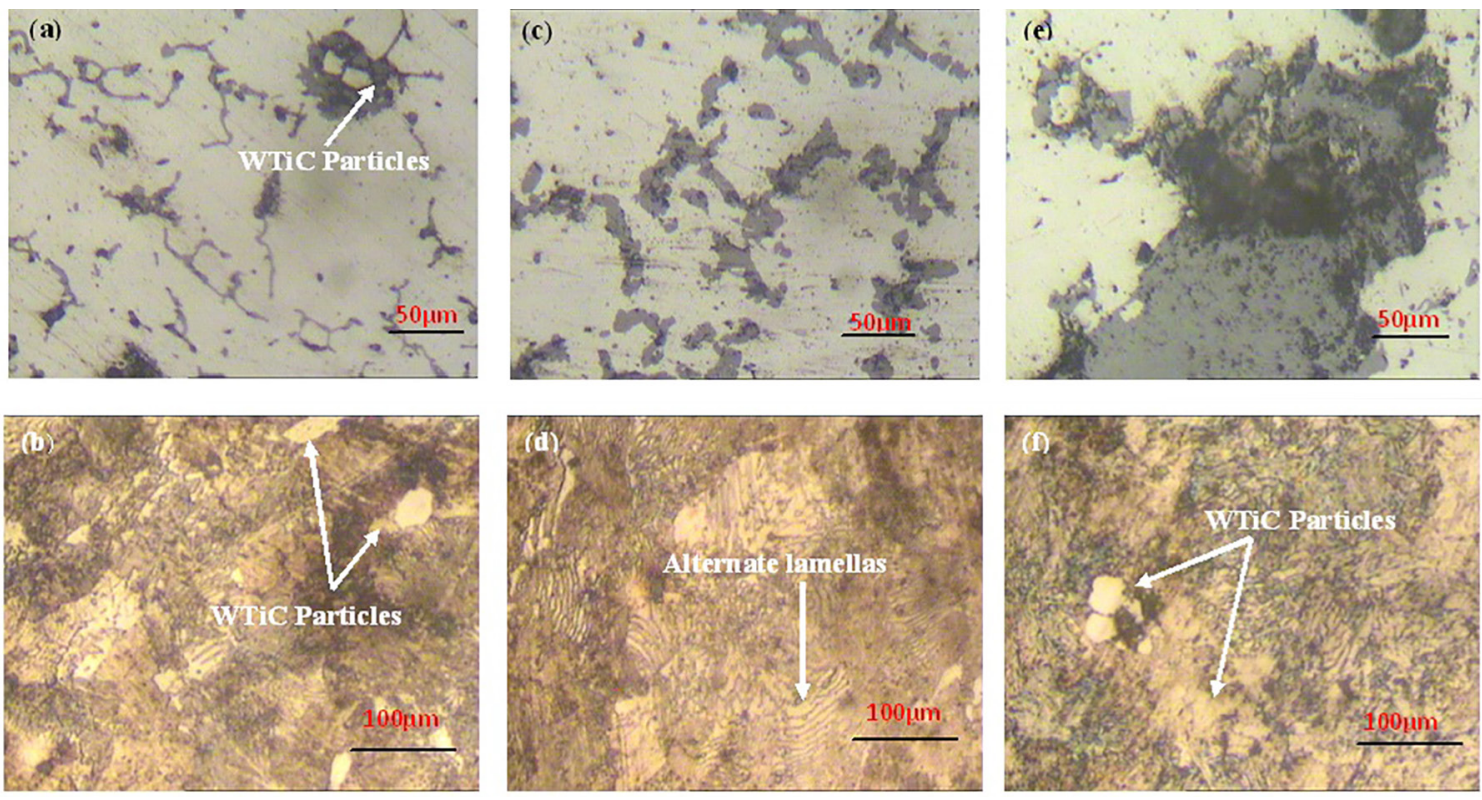

Figure 2. Optical micrographs of the as-sintered and hot extruded P/M alloy steels. (a) \& (b) Fe-1\%C-1\%W-1\%Ti; (c) \& (d) Fe- $1 \% \mathrm{C}$ $2 \% \mathrm{~W}-1 \% \mathrm{Ti}$; (e) \& (f) $\mathrm{Fe}-1 \% \mathrm{C}-4 \% \mathrm{~W}-1 \% \mathrm{Ti}$
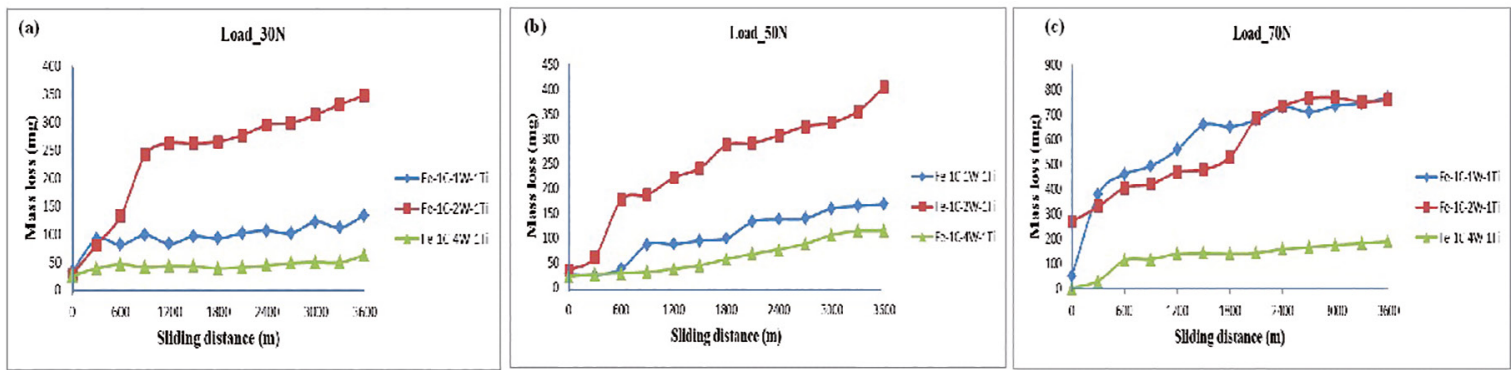

Figure 3. Dry sliding wear behaviour ofhot extruded P/M low alloy steel at different loads (a) $30 \mathrm{~N}$; (b) $50 \mathrm{~N}$; (c) $70 \mathrm{~N}$

loss during the wear test called Delamination wear ${ }^{6}$. At the applied load of $30 \mathrm{~N}$ (Figure 3a) the amount of mass loss is lower for Fe-1C-1W-1 Ti and Fe-1C-4W-1 Ti alloy steel due to the removal of the thin oxide layer present on the surface and further to increase in sliding distance it remains constant. The same trend was also observed for the applied load of $50 \mathrm{~N}$. But sliding at higher loads $(70 \mathrm{~N})$ under dry conditions causes heat generation at the interface leads to formation of an oxide layer in the surface due to the hard phase WTiC particles present. As the sliding distance increases the delamination of thin oxide film continuously results in more wear for Fe-1C-1W-1 Ti and Fe-1C-2W-1 Ti whereas for Fe-1C-4W-1 Ti, mass loss was observed to be minimum (Figure 3c). I.e. increasing in percentage of $\mathrm{W}$ (Fe-1C-4W-1 Ti) in the alloy enhances the wear resistance of the extruded P/M alloy steel due to more carbide (WC) embedded along with the Ti in the grain boundaries.

\subsection{Frictional coefficient of sintered/hot extruded} $P / M$ steels alloyed with Tungsten and Titanium with the effect of applied load and sliding speed

Figure 4(a-c) depicts the variation of the frictional coefficient of sintered /hot extruded $\mathrm{P} / \mathrm{M}$ plain carbon steels, alloyed with tungsten and titanium (Fe-1\%C-1\%W-1\%Ti, Fe$1 \% \mathrm{C}-2 \% \mathrm{~W}-1 \% \mathrm{Ti}, \mathrm{Fe}-1 \% \mathrm{C}-4 \% \mathrm{~W}-1 \% \mathrm{Ti}$ ) for different loads.

The frictional coefficient values ranged about 0.14 to 0.68 for the hot extruded alloy steels. For Fe-1C-1W-1Ti varies from 0.31 to 0.64 , for $\mathrm{Fe}-1 \mathrm{C}-2 \mathrm{~W}-1 \mathrm{Ti}$ ranges 0.17 to 0.68 whereas for $\mathrm{Fe}-1 \mathrm{C}-4 \mathrm{~W}-1 \mathrm{Ti}$ varies from 0.14 to 0.64 . The coefficient of friction of Fe-1C-4W-1 Ti was observed to be higher at low level of applied load $(30 \mathrm{~N})$ compared to other two alloy steels might be due to the high hardness because of more WTiC presence. From the Figure 4(b) $(50 \mathrm{~N})$, the initial frictional coefficient of Fe-1C-2W-1Ti 

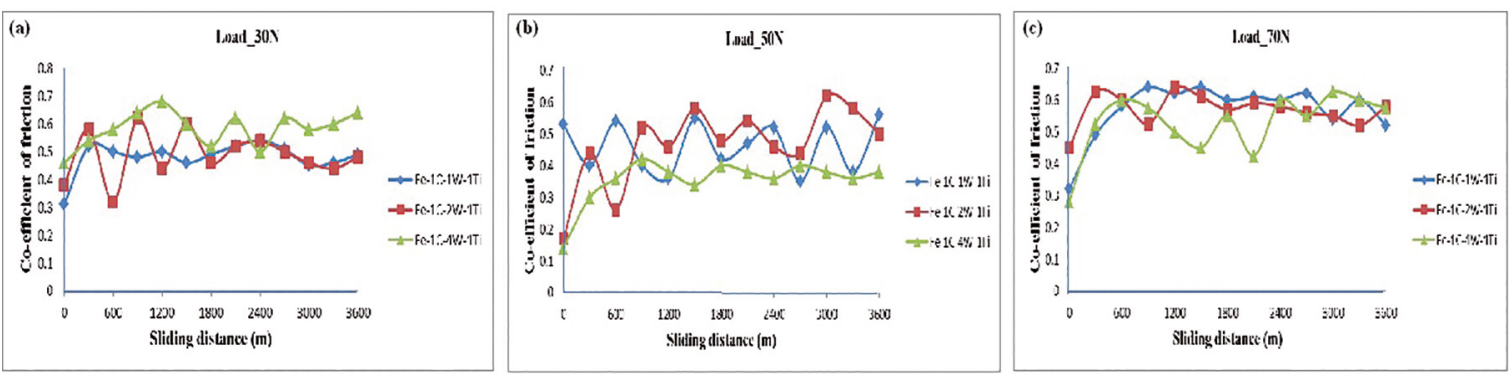

Figure 4. Variation of the frictional coefficient of hot extruded P/M low alloy steel at different loads (a) $30 \mathrm{~N}$; (b) $50 \mathrm{~N}$; (c) $70 \mathrm{~N}$

and $\mathrm{Fe}-1 \mathrm{C}-4 \mathrm{~W}-1 \mathrm{Ti}$ is low due to contact of oxide layers and steel disc material. As the sliding distance increases breaking and delamination of thin surface oxide layer leading to the metal-to-metal contact causes an increase in the coefficient of friction. At higher loads $(70 \mathrm{~N})$ the coefficient of friction increased gradually as the sliding distance increases. The frictional force increase for Fe-1C-1W-1Ti and Fe-1C-2W-1Ti alloyed steel due to increases in the interface temperature leads to thermal softening thereby increase the wear rate (Figure 4c). For Fe-1C-4W-1Ti extruded steel due to the more hard phase tungsten carbide (WC) embedded with Ti in the grain boundaries increases the interface temperature results in formation of an oxide layer reduces the direct metal to metal contact thereby frictional coefficient decreases and wear rate also decreases ${ }^{7}$.

\subsection{Wear pattern of hot extruded P/M steels alloyed with Tungsten and Titanium}

Figure 5(a-c) depicts the wear pattern of hot extruded $\mathrm{P} / \mathrm{M}$ plain carbon steels, alloyed with tungsten and titanium at $70 \mathrm{~N}$ of applied load.

From the Figure 5(a \& b) it has been observed that crater and small grooves formed at the worn surface due to higher hardness secondary phase WTiC presence, causes a rise in interface temperature at higher loads results in thermal softening of the material causing removal of the thin metal layer from the surface which cause the propagation of microcracks $^{8}$. The continuous fracture of thin layer leads to higher mass loss and further leads to formation of wear fragments with increase in sliding distance, so called delamination, this increases the frictional coefficient (Figure 4c). Delamination is a main mechanism responsible for removal of material. Failure by a delamination process is clearly indicated by the shape of the debris particles. The uniform wear pattern was observed in the alloy Fe-1C-4W-1Ti (Figure 5c) due to the presence of more carbide (WC) embedded with the $\mathrm{Ti}$ in the grain boundaries enhances the wear resistance also it is evident from (Figure 2f).

\subsection{XRD analysis of hot extruded P/M steels alloyed with Tungsten and Titanium}

Figure 6 depicts the XRD spectra analysis of wear debris of Fe-1C-2W-1 Ti hot extruded P/M steels, alloyed with tungsten and titanium at $70 \mathrm{~N}$ of applied load. The XRD pattern of the debris revealed that major phases formed during the dry sliding operation. The major amounts of $\mathrm{Fe}_{2} \mathrm{O}_{3}, \mathrm{Fe}_{3} \mathrm{O}_{4}$ and few traces of WTiC, WC, TiC were observed. It is evident from the XRD analysis that due to the high temperature produced between the specimen and the disc at higher loads leads to the oxide layer in the absence of lubricant. Moreover Ti and W based carbides had fractured under high loads, but not oxidized because $\mathrm{TiO}_{2}$ might be act as solid lubricant at high
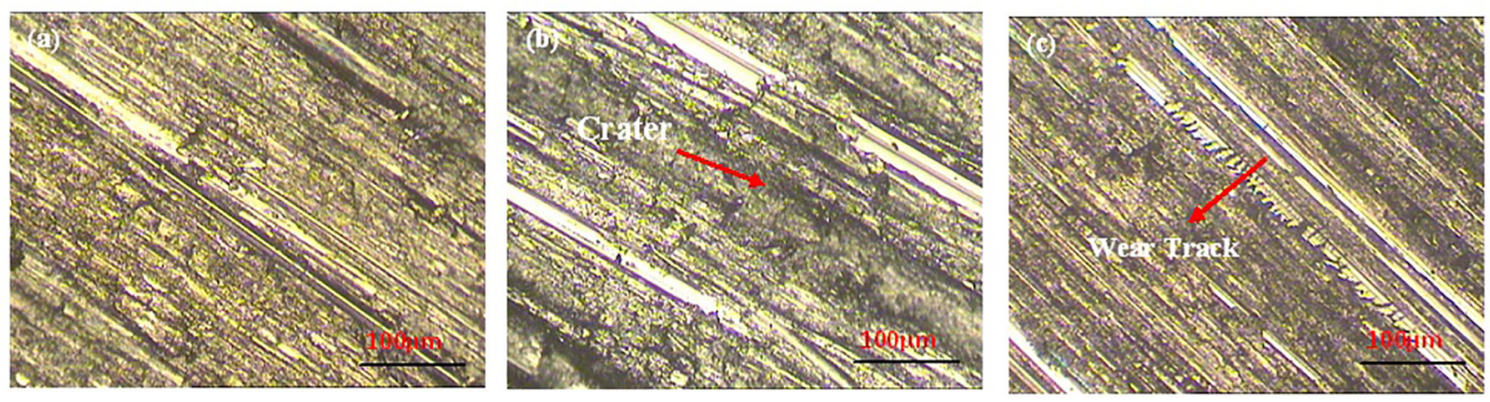

Figure 5. Wear Pattern of hot extruded P/M alloy steels (a) Fe-1\%C-1\%W-1\%Ti; (b) Fe-1\%C-2\%W-1\%Ti; (c) Fe-1\%C-4\%W-1\%Ti 


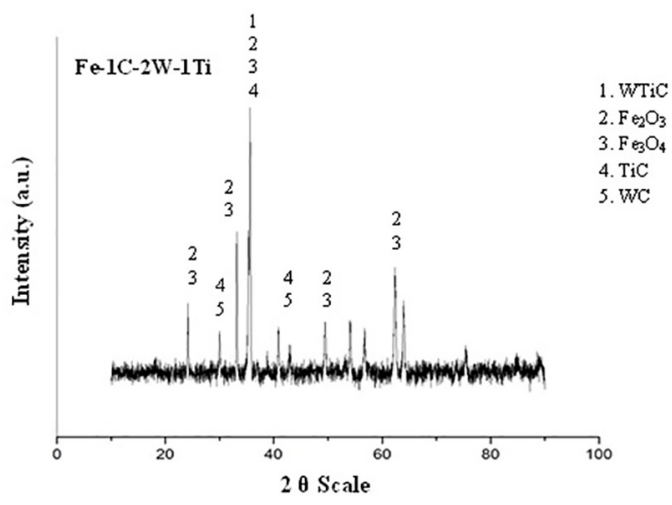

Figure 6. XRD spectra analysis of wear debris of Fe-1\%C-2\%W$1 \%$ Ti hot extruded $\mathrm{P} / \mathrm{M}$ alloy steel

temperature ${ }^{14}$. The fracture of this oxide layer and WTiC act as a third body which is trapped between the mating surface further lead to formation of wear fragments results in higher mass loss during the wear test ${ }^{15}$.

\subsection{SEM images of hot extruded P/M steels alloyed with Tungsten and Titanium}

Figure $7(\mathrm{a}, \mathrm{b})$ depicts the SEM image of maximum worn out surface and wear debris of Fe-1C-2W-1Ti hot extruded $\mathrm{P} / \mathrm{M}$ steels alloyed with tungsten and titanium at $70 \mathrm{~N}$ of applied load. The hard WTiC particles embedded in the ferritic grain matrix is evident from the SEM image (Figure 7a) attributes the higher hardness thereby rise in interface temperature owing in thermal softening of the materials results in the micro-cutting (thin metal layer) from the surface causes higher mass loss further leads to formation of wear fragments at higher loads. Whereas the wear debris shown in the Figure 7b includes thin oxide particles, microcutting and delamination flakes. Crater and grooves that are perpendicular to the sliding direction results in wear debris formation in the form of microchips and flakes.
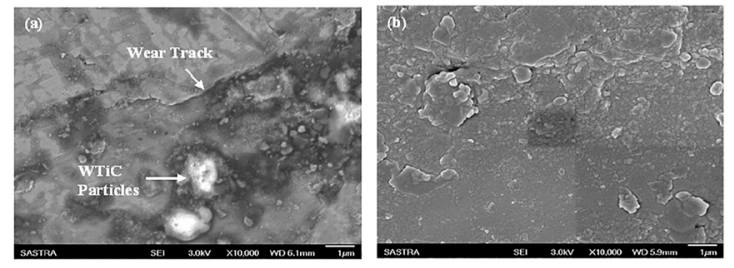

Figure 7. SEM images of $\mathrm{Fe}-1 \% \mathrm{C}-2 \% \mathrm{~W}-1 \% \mathrm{Ti}$ hot extruded $\mathrm{P} / \mathrm{M}$ alloy steel (a) Maximum Worn out surface (b) Wear debris

\section{Conclusions}

The present study investigates the dry sliding wear behavior of sintered/hot extruded $\mathrm{P} / \mathrm{M}$ plain carbon steels, alloyed with tungsten and titanium (Fe-1C-1W-1Ti, Fe-1C-2W-1Ti and Fe-1C-4W-1Ti) and the following points were concluded.
- The mass loss of Fe-1C-2W-1Ti increases linearly irrespective of applied load and sliding distance compared to Fe-1C-1W-1Ti, Fe-1C-4W-1Ti due to the presence of secondary phase hard WTiC leads to the rise in interface temperature results in thermal softening of the material which cause propagation of micro-cracks, further leads to formation of wear fragments.

- The microstructure of Fe-1C-4W-1Ti exhibits Widmanstatten type ferrite and bainite due to the more presence of harder secondary phase WTiC particles embedded in the ferrite-pearlite grains and strengthen the grain boundary region thereby decrease in mass loss.

- The uniform wear pattern was observed in the alloy Fe-1C-4W-1Ti due to the uniform distribution of carbide (WC) embedded with the $\mathrm{Ti}$ in the grain boundaries which enhances the wear resistance ${ }^{15}$.

- The XRD pattern of the wear debris revealed that major amounts of $\mathrm{Fe}_{2} \mathrm{O}_{3}, \mathrm{Fe}_{3} \mathrm{O}_{4}$ and few traces of WTiC, WC, TiC were observed.

- Delamination is a main wear mechanism for $\mathrm{W}$ and Ti alloyed P/M steel and it is clearly indicated by the shape of the debris particles at higher loads.

\section{References}

1. Hortenhuber A. PM camshaft technology. Metal Powder Report. 1992;47(1):16-19.

2. Straffelini G, Molinari A. Effect of hardness on rolling-sliding damage mechanisms in PM alloys. Powder Metallurgy. 2001;44(4):344-350.

3. Haynes R. Development of sintered low alloy steels. Powder Metallurgy. 1989;32(2):140-146.

4. Simchi A, Danninger H. Effect of porosity on delamination wear of sintered plain iron. Powder Metallurgy. 2004;47(1):73-80.

5. Straffelini G, Molinari A. Dry sliding wear of ferrous PM materials. Powder Metallurgy. 2001;44(3):48-52.

6. Wang J, Danninger H. Dry sliding wear behaviour of molybdenum alloyed sintered steels. Wear. 1998;222(1):49-56.

7. Dhanasekaran S, Gnanamoorthy R. Dry sliding friction and wear characteristics of $\mathrm{Fe}-\mathrm{C}-\mathrm{Cu}$ alloy containing molybdenum di sulphide. Materials \& Design. 2007;28(4):1135-1141.

8. Ceshini L, Plombarini G, Sambogna G, Firrao D, Scavino G, Ubertalli G. Friction and wear behaviour of sintered steels submitted to sliding and abrasion tests. Tribology International. 2006;39(8):748-755

9. Zuomin L, Childs THC. The study of wear characteristics of sintered high speed steels containing $\mathrm{CaF}_{2}, \mathrm{MnS}$, TiC additives at elevated temperature. Wear. 2004;257(3-4):435-440.

10. Molinari A, Straffelini G, Campestrini P. Influence of microstructure on impact and wear behavior of sintered $\mathrm{Cr}$ and Mo steel. Powder Metallurgy. 1999;42(3):235-241. 
11. Bose A, Sadangi R, German RM. A review on alloying in tungsten heavy alloys. In: Supplemental Proceedings: Materials Processing and Interfaces, Volume 1. Hoboken: Wiley; 2012. p. 455-465.

12. Prabu SS, Prathiba S, Asokan MA, Jain A, Jain NK, Chourasiya PK. Investigations on Dry Sliding Wear Behaviour of Sintered/ Extruded P/M Alloy Steels (Fe-C-W-Ti). Procedia Engineering. 2014;97:2119-2126
13. Wang MC. Properties of High Density Powder Forged Iron Based Alloy. Powder Metallurgy. 1994;37(3):201-205.

14. Degnan CC, Shipway PH, Wood JV. Elevated temperature sliding wear behaviour of TiC-reinforced steel matrix composites. Wear. 2001;251(1-12):1444-1451.

15. Leonard AJ, Rainforth WM. Wear behaviour of tool steels with added (WTi)C particles. Wear. 2003;255(1-6):517-526. 